\title{
An Evidence-Based Definition of Lifelong Premature Ejaculation: Report of the International Society for Sexual Medicine (ISSM) Ad Hoc Committee for the Definition of Premature Ejaculation
}

\author{
Chris G. McMahon, MD, ${ }^{1}$ Stanley E. Althof, $\mathrm{PhD},{ }^{2}$ Marcel D. Waldinger, MD, $\mathrm{PhD},{ }^{3}$ \\ Hartmut Porst, MD, ${ }^{4}$ John Dean, MD, ${ }^{5}$ Ira D. Sharlip, MD, ${ }^{6}$ P.G. Adaikan, PhD, DSc, ACS, ${ }^{7}$ \\ Edgardo Becher, MD, ${ }^{8}$ Gregory A. Broderick, MD, ${ }^{9}$ Jacques Buvat, MD, ${ }^{10}$ Khalid Dabees, MD, ${ }^{11}$ \\ Annamaria Giraldi, MD, PhD, ${ }^{12}$ François Giuliano, MD, PhD, ${ }^{13}$ Wayne J.G. Hellstrom, MD, ${ }^{14}$ \\ Luca Incrocci, MD, PhD, ${ }^{15}$ Ellen Laan, PhD, ${ }^{16}$ Eric Meuleman, MD, ${ }^{17}$ Michael A. Perelman, PhD, ${ }^{18}$ \\ Raymond C. Rosen, PhD, ${ }^{19}$ David L. Rowland, PhD, ${ }^{20}$ and Robert Segraves, MD, PhD ${ }^{21}$

\begin{abstract}
${ }^{1}$ Australian Center for Sexual Health, Sydney, Australia; ${ }^{2}$ Case Western Reserve University School of Medicine, Center for Marital and Sexual Health of South Florida, West Palm Beach, FL, USA; ${ }^{3}$ Psychiatry and Neurosexology, Leyenburg Hospital, The Hague, the Netherlands; ${ }^{4}$ Private Urological Practice, Hamburg, Germany; ${ }^{5}$ The Salisbury Clinic, South Brent, UK; ${ }^{6}$ University of California San Francisco, San Francisco, CA, USA; ${ }^{7}$ Department of Obstetrics and Gynaecology, National University Hospital, National University of Singapore, Singapore, Singapore; ${ }^{8}$ Division of Urology, University of Buenos Aires, Argentina; ' $D$ epartment of Urology, Mayo Clinic College of Medicine, Jacksonville, FL, USA; ${ }^{10}$ Center ETPARP, Lille, France; ${ }^{11}$ Cairo, Egypt; ${ }^{12}$ Sexological Clinic, Division of Sexological Research, Rigshospitalet Section 7111, Copenhagen, Denmark; ${ }^{13}$ Raymond Poincaré Hospital_Department of Physical Medicine and ${ }^{15}$ Erasmus MC-Daniel den Hoed Cancer Center, Rotterdam, the Netherlands; ${ }^{16}$ Department of Sexology and Psychasomatic Obstetrics and Gynaecology, Academic Medical Center, University of Amsterdam, Amsterdam, the Netherlands; ${ }^{17}$ Department of Urology, Free University Medicial Center, Amsterdam, the Netherlands; ${ }^{18}$ Weill Medical College of Cornell University, Departments of Psychiatry, Reproductive Medicine, and Urology, New York, NY, USA; ${ }^{19}$ Department of Psychiatry, UMDNJ_Robert Wood Johnson Medical School, Piscataway, NJ, USA; ${ }^{20}$ Valparaiso University, Valparaiso, IN, USA; ${ }^{21}$ MetroHealth-Psychiatry, Cleveland, OH, USA
\end{abstract} \\ Rehabilitation, Garches, France; ${ }^{14}$ Department of Urology, Tulane University School of Medicine, New Orleans, LA, USA;
}

DOI: 10.1111/j.1743-6109.2008.00901.x

\section{A B S T R A C T}

Introduction. The medical literature contains several definitions of premature ejaculation (PE). The most commonly quoted definition, the American Psychiatric Association's Diagnostic and Statistical Manual of Mental Disorders-Fourth Edition-Text Revision, and other definitions of PE are all authority based rather than evidence based, and have no support from controlled clinical and/or epidemiological studies.

Aim. The aim of this article is to develop a contemporary, evidence-based definition of PE.

Metbods. In August 2007, the International Society for Sexual Medicine (ISSM) appointed several international experts in PE to an Ad Hoc Committee for the Definition of Premature Ejaculation. The committee met in Amsterdam in October 2007 to evaluate the strengths and weaknesses of current definitions of PE, to critique the evidence in support of the constructs of ejaculatory latency, ejaculatory control, sexual satisfaction, and personal/ interpersonal distress, and to propose a new evidence-based definition of PE.

Results. The committee unanimously agreed that the constructs that are necessary to define PE are rapidity of ejaculation, perceived self-efficacy and control, and negative personal consequences from PE. The committee proposed that lifelong PE be defined as ". . . a male sexual dysfunction characterized by ejaculation which always or nearly always occurs prior to or within about one minute of vaginal penetration, and the inability to delay ejaculation on all or nearly all vaginal penetrations, and negative personal consequences, such as distress, bother, frustration and/or the avoidance of sexual intimacy." This definition is limited to men with lifelong PE who engage in vaginal intercourse. The panel concluded that there are insufficient published objective data to propose an evidence-based definition of acquired PE.

Conclusion. The ISSM definition of lifelong PE represents the first evidence-based definition of PE. This definition will hopefully lead to the development of new tools and Patient Reported Outcome measures for diagnosing and assessing the efficacy of treatment interventions and encourage ongoing research into the true prevalence of this disorder and the efficacy of new pharmacological and psychological treatments. McMahon CG, Althof SE, Waldinger MD, Porst H, Dean J, Sharlip ID, Adaikan PG, Becher E, Broderick GA, Buvat J, Dabees K, Giraldi A, Giuliano F, Hellstrom WJG, Incrocci L, Laan E, Meuleman E, Perelman MA, Rosen RC, Rowland DL, and Segraves R. An evidenced-based definition of lifelong premature ejaculation: Report of the 
International Society for Sexual Medicine (ISSM) Ad Hoc Committee for the definition of premature ejaculation. J Sex Med ${ }^{* *} ; * *: * *-* *$.

Key Words. Premature Ejaculation; Definition; Intravaginal Ejaculatory Latency Time; Ejaculatory Control; Sexual Satisfaction; Personal Distress; Interpersonal Distress; Negative Personal Psychological Consequences

\section{Introduction}

$\mathrm{T}$ he premise that premature ejaculation $(\mathrm{PE})$ is a psychosomatic disturbance was first suggested by Schapiro in 1943 [1]. For many years, behavioral psychotherapy was the cornerstone of treatment and included techniques such as the stop-start method with or without the squeeze technique $[2,3]$. The on-demand use of topical anesthetic cream to delay ejaculation was first described in the 1930s and is regarded as the oldest drug treatment of PE [1]. Over the past 20-30 years, the $\mathrm{PE}$ treatment paradigm has expanded to include drug treatment. During the 1970s and 1980s, double-blind, placebo controlled studies demonstrated the efficacy of clomipramine, the most serotonergic tricyclic antidepressant in delaying ejaculation [4,5]. Subsequent animal and human sexual psychopharmacological studies have demonstrated that serotonin and 5-HT receptors are involved in ejaculation and confirm a role for selective serotonin reuptake inhibitors (SSRIs) in the treatment of PE [6-12]. Over the past 15 years, an increasing number of well-controlled, evidencebased studies have demonstrated the efficacy and safety of SSRIs in delaying ejaculation, confirming their role as first-line agents for the treatment of lifelong and acquired PE [13]. More recently, there has been increased attention to the psychosocial consequences of PE, its epidemiology, its etiology, and its pathophysiology by both clinicians and the pharmaceutical industry [14-19]. The pharmaceutical industry has contributed to our current understanding of PE over the past 2-3 years. Most of the recent large $\mathrm{PE}$ observational studies have been designed and conducted, with data analyzed, interpreted, and reported by industry employees and industry-sponsored investigators. Continued industry participation in evidence-based $\mathrm{PE}$ research is encouraged as it is likely to benefit the common interest of encouraging effective and responsible use of investigational and existing drugs, improved treatment adherence, and improved patient outcomes [20].
The population of men with $\mathrm{PE}$ is not homogenous. In 1943, Schapiro classified PE as either primary (lifelong) or secondary (acquired) [1]. Recently, Waldinger et al. expanded this classification to include lifelong $\mathrm{PE}$, acquired $\mathrm{PE}$, natural variable $\mathrm{PE}$, and premature-like ejaculatory dysfunction [21]. Lifelong PE is a syndrome characterized by a cluster of core symptoms including early ejaculation at nearly every intercourse within $30-60$ seconds in the majority of cases $(80 \%)$ or between 1 and 2 minutes (20\%), with every or nearly every sexual partner and from the first sexual encounters onward. Acquired PE differs in that sufferers develop early ejaculation at some point in their life, having previously had normal ejaculation experiences. Acquired $\mathrm{PE}$ may be because of psychological or relationship problems, erectile dysfunction (ED), prostatitis or thyroid dysfunction [22-25]. In natural variable $\mathrm{PE}$ the ejaculation time is never consistently rapid but merely coincidental and situational. This type of $\mathrm{PE}$ should be regarded as a normal variation in sexual performance and is characterized by inconsistent and irregular early ejaculation, often with reduced ejaculatory control [26]. Men with premature-like ejaculatory dysfunction complain of PE but have a normal ejaculatory latency of 3-6 minutes. It is characterized by a preoccupation with a subjective but false perception of $\mathrm{PE}$ with an ejaculatory latency within the normal range but often with reduced ejaculatory control.

Research into the treatment and epidemiology of PE is heavily dependent on how PE is defined. The medical literature contains several univariate and multivariate operational definitions of $\mathrm{PE}$ [3,27-34]. Each of these definitions characterize men with PE using all or most of the accepted dimensions of this condition: ejaculatory latency, perceived ability to control ejaculation, reduced sexual satisfaction, personal distress, partner distress, and interpersonal or relationship distress. Although the most commonly quoted definition, that of the Diagnostic and Statistical Manual of Mental Disorders-Fourth Edition-Text Revision 
(DSM-IV-TR), and other definitions of PE differ substantially, they are all authority based, i.e., expert opinion without explicit critical appraisal [35], rather than evidence based and have no support from controlled clinical and/or epidemiological studies. Additionally, these definitions are primarily conceptual in nature, are vague in terms of operational specificity, and rely on the subjective interpretation of the concepts by the clinician. This lack of agreement as to what constitutes $\mathrm{PE}$ continues to hamper clinical research into the etiology and management of this condition, and the development of Patient Reported Outcomes (PROs) to diagnose and assess treatment intervention strategies [36].

In August 2007, the International Society for Sexual Medicine (ISSM) appointed several international experts in PE to an Ad Hoc Committee for the Definition of Premature Ejaculation and convened a meeting in Amsterdam in October 2007 for the purpose of developing a contemporary, evidence-based definition of $\mathrm{PE}$. The concept of evidence-based medicine was interpreted by the committee as the integration of individual clinical expertise with the best available external clinical evidence from systematic research [37]. The meeting was supported by unrestricted research grants from Plethora Solutions and Johnson and Johnson. However, the ISSM required complete independence from industry during the development of the new definition of PE. There were no industry representatives at the meeting and there was no attempt by industry to influence any part of the development process at any time. The committee was chosen by peer recommendation from 10 experts and opinion leaders in sexual medicine, each of whom was asked to nominate, based on expertise in PE, 10 candidates. Thirty-five names were suggested by at least one peer; 22 of the 35 were nominated by two peers or more; 12 names were nominated by three peers or more and a few names were nominated eight times. Several additional experts in sexual medicine, including three women, were invited despite not being nominated in order to provide a balance of opinion, knowledge, gender, and geography. Ultimately, 26 experts were invited to the meeting and 21 attended. These 21 included several of the world's most highly recognized experts on PE and included eight psychologists or psychiatrists, seven urologists, one sexual health physician, one primary care physician, one neuro-urology researcher, one clinical pharmacologist, one endocrinologist, and one radiation oncologist. All of the attendees were ISSM members. The meeting was organized by the current ISSM president Ira Sharlip, chaired by the ISSM Standards Committee chairman Hartmut Porst, and facilitated by the ISSM president-elect John Dean.

This article chronicles the development of current definitions of $\mathrm{PE}$ and details their strengths and weaknesses, critiques the evidence in support of the constructs of ejaculatory latency, ejaculatory control, sexual satisfaction, and personal/interpersonal distress, and proposes a new definition of PE.

\section{Operationalizing PE Variables and Constructs}

A construct is a nonobservable, latent variable that is presumed to exist, is an attribute of people, and is used to help explain or predict variation in responses or behavior [38]. In the study of PE, rapidity of ejaculation, perceived ejaculatory selfefficacy or control, and negative personal and interpersonal consequences (e.g., distress) represent constructs that require operationalization. Operationalization is the process of defining a construct or variable by the development of a measure, procedure, or operation for the identification of instances of that construct or variable.

Operationalization and the careful determination of cutoffs for each variable will minimize but never completely eliminate inclusion (false positive) or exclusion errors (false negative) of PE classification of those who have PE vs. those who do not. More restrictive criteria are more likely to result in errors of exclusion whereas more lenient criteria may result in errors of inclusion. Determination of cutoff values for variables must include careful consideration of the significance and impact of the resulting classification errors on the diagnosis of $\mathrm{PE}$. The use of a multivariate approach to defining and diagnosing $\mathrm{PE}$ will minimize these errors of classification.

The constructs of $\mathrm{PE}$ are difficult to define and operationalize. They can be operationalized using a variety of measures and no single operational measure will completely and precisely capture the essence of each construct [39]. For example, rapidity of ejaculation can be operationalized using estimation of ejaculation latency, stopwatch measurement of ejaculation latency or thrust counting by either the man or his partner. Similarly, perceived ejaculatory self-efficacy and ejaculatory control can be operationalized by measurement of improvements in ejaculation latency time during attempts to delay ejaculation 
using self-estimation or stopwatch measurements or the calculation of the relative fold-increase in ejaculatory latency, or by the measurement of the subjective feeling of ejaculatory control using validated single or multi-item multi-domain $\mathrm{PE}$ inventories. And finally, the negative personal and interpersonal consequences of $\mathrm{PE}$ can be operationalized by measurement of sexual or global levels of distress, bother, frustration, anxiety, depression, confidence, self-esteem and quality of life, and sexual satisfaction for both men and their partners using validated single or multiitem multi-domain PE inventories, omnibus sexual inventories, quality-of-life and relationshipquality inventories. Other concerns with operationalizing distress and bother relate to the quality of the PRO employed and its psychometric characteristics.

Furthermore, the measures of rapidity of ejaculation, perceived self-efficacy and control, and negative personal and interpersonal consequences are interrelated and may be confounded by each other and by multiple other variables. These variables include the overall physical and psychological health of the man and his partner, the frequency of sexual intercourse, the period of time elapsed since the previous ejaculation, the duration and content of foreplay, the sexual position, the depth, force, and frequency of penile thrusting, the partner's pelvic floor muscle tone, and the extent of partner vaginal lubrication. Clearly, the process of $\mathrm{PE}$ construct operationalization will ultimately determine who is diagnosed with PE as well as the types and consequences of errors that result from implementation of the diagnostic procedure [39].

\section{The ISSM Definition of PE}

Members of the ISSM Ad Hoc Committee for the Definition of Premature Ejaculation unanimously agreed that the constructs that are necessary to define PE are time from penetration to ejaculation, inability to delay ejaculation, and negative personal consequences from PE. The ISSM Ad Hoc Committee for the Definition of Premature Ejaculation defines lifelong PE as a male sexual dysfunction characterized by

- ejaculation that always or nearly always occurs prior to or within about one minute of vaginal penetration;

- the inability to delay ejaculation on all or nearly all vaginal penetrations; and
- negative personal consequences such as distress, bother, frustration, and/or the avoidance of sexual intimacy.

The committee agreed that published objective evidence on PE is limited to studies of men with lifelong $\mathrm{PE}$ engaging in vaginal intercourse. However, the committee regarded this definition as likely to apply to men with lifelong PE who engage in sexual activities other than vaginal intercourse. The panel concluded that there are insufficient published objective data to propose an evidence-based definition of acquired PE.

\section{History of Definitions}

For the first part of the 20th century there was no official definition of $\mathrm{PE}$, although most psychiatrists and psychoanalysts considered $\mathrm{PE}$ as ejaculation within 30-60 seconds of vaginal intromission. However, there was no evidence to support this unwritten consensus [40]. This latency-based definition was rejected by Masters and Johnson, who defined PE as a man's inability to delay ejaculation sufficient for the partner to reach orgasm in $50 \%$ of intercourse episodes [3]. However, an inherent problem exists in defining a man as dysfunctional based on the sexual responsiveness of his partner. Masters and Johnson's partner response-based definition implied that any man whose partner has difficulty in reaching orgasm could be labeled a premature ejaculator and is at odds with the report that only $30 \%$ of women achieve orgasm during sexual intercourse regardless of the extent of their partner's ejaculatory control and latency.

\section{Diagnostic and Statistical Manual of Mental Disorders-Third Edition (DSM-III) and Diagnostic and Statistical Manual of Mental Disorders-Fourth Edition (DSM-IV) Definitions of PE}

The first official definition of $\mathrm{PE}$ was proposed in 1980 by the American Psychiatric Association (APA) in the DSM-III [41]. In the DSM-III, $\mathrm{PE}$ was defined as "Ejaculation that occurs before the individual wishes it, because of recurrent and persistent absence of reasonable voluntary control of ejaculation and orgasm during sexual activity" [41]. The criterion of "reasonable voluntary control" was removed in the revision of the DSMIII (DSM-III-R) and in the subsequent DSM-IV and DSM-IV-TR editions and was replaced by the criterion of a "short ejaculation time." In the 
DSM-III-R, PE was defined as "Persistent or recurrent ejaculation with minimal sexual stimulation before, on, or shortly after penetration and before the person wishes it. The clinician must take into account factors that affect duration of the excitement phase, such as age, novelty of the sexual partner or situation, and recent frequency of sexual activity" [42]. The later DSM-IV and DSMIV-TR editions maintained this definition but added the additional criterion "the disturbance causes marked distress or interpersonal difficulty" $[27,43]$.

\section{International Classification of Diseases (ICD-10) Definition of PE}

The World Health Organization's ICD-10 of 1993 defines PE as "The inability to control ejaculation sufficiently for both partners to enjoy sexual interaction" and as "an inability to delay ejaculation sufficiently to enjoy lovemaking, and manifest as either of the following: (i) occurrence of ejaculation before or very soon after the beginning of intercourse (if a time limit is required: before or within 15 seconds of the beginning of intercourse) and (ii) ejaculation occurs in the absence of sufficient erection to make intercourse possible" [28]. The ICD-10 definition of PE limits the construct of "control" by the criterion "very short" ejaculation time of within 15 seconds of penetration but provides no supportive empirical evidence.

\section{The Criterion of a "Short Ejaculation Time"}

The DSM-IV-TR and the ICD-10 definitions of $\mathrm{PE}$ require that ejaculation time is "short" and "very short," respectively. Although the ICD-10 definition specifies an ejaculation time cutoff of 15 seconds, the Diagnostic and Statistical Manual of Mental Disorders (DSM) definitions fail to provide any cutoff points. The absence of a time criterion in the DSM-III definition and a clear ejaculation time cutoff point in the subsequent DSM-III-R and DSM-IV definitions has resulted in the use of a broad range of latencies for the diagnosis of PE in clinical trials. Ejaculation latencies quoted in various published articles include within 1 minute [44], 2 minutes [45,46], 3 minutes [47], 4 minutes [48], 5 minutes [49-51], and 7 minutes after vaginal penetration [52]. These ejaculation latencies cutoff points were subjectively chosen by the various authors and were not based on objective measurements of ejaculation latency in men with PE. The failure of DSM definitions to specify an ejaculation latency cutoff point means that a patient in the control group of one study may very well be in the PE group of a second study, making comparison of studies difficult and generalization of their data to the general $\mathrm{PE}$ population impossible.

\section{Authority-Based vs. Evidence-Based Definition of PE}

The utility and application of the DSM-III, DSMIII-R, DSM-IV, DSM-IV-TR, and ICD-10 definitions of $\mathrm{PE}$ are limited as they are authority based and rely solely upon the opinion and clinical experience of experts who participated in the various DSM and ICD committees, i.e., expert opinion without explicit critical appraisal, and not well-controlled, evidence-based clinical research [53]. Similarly, the Second International Consultation of Sexual Dysfunctions (ICSD-2) and the American Urological Association (AUA) definitions of PE, which were derived from the DSMIV-TR, must also be regarded as authority based $[30,32,53]$.

\section{The Need for an Evidence-Based Definition of PE}

The validity of the DSM definitions continues to be the subject of debate with a substantial polarization of opinion. For critics of the DSM definitions, words such as "persistent," "recurrent," "minimal," and "shortly after" are vague, multiinterpretable, and lack quantification [36,54,55]. They contend that the absence of a specific ejaculation time cutoff point to operationalize "shortly after penetration or before the person wishes" has led to the incorrect application of the DSM definitions in clinical research [56]. Many support the development of a new definition in the pending Diagnostic and Statistical Manual of Mental Disorders-Fifth Edition (DSM-V) [26,57-60]. However, criticism of the current DSM-IV-TR definition is not unanimous and a number of clinicians regard it as valid and regard both revision or the development of a new definition in the pending DSM-V as unnecessary [61,62].

However, the concern about the validity and application of the DSM-IV-TR definition is also shared by regulatory agencies such as the U.S. Food and Drug Administration. The lack of evidence-based criteria may serve as an obstacle for these authorities to interpret and assess data from clinical trials of PE investigational drugs. For these reasons, the ISSM Standards Committee has 
recommended that a new evidence-based definition of PE should be formulated.

\section{Rationale for the Inclusion of the Intravaginal Ejaculation Latency Time (IELT) in the ISSM Definition of PE}

In 1994, Waldinger et al. introduced the IELT in an attempt to operationalize ejaculation latency in a definition of PE [63]. The IELT was defined as the time between vaginal intromission and intravaginal ejaculation [63]. This measure unequivocally defines ejaculatory latency and has contributed to more objective research in men with and without PE. Recently, it was proposed that Masturbation Ejaculation Latency Time, Oral Ejaculation Latency Time, and Anal Ejaculation Latency Time be adopted as measures for research in heterosexual or homosexual men with and without partners [64].

\section{The IELT in Men with Lifelong PE}

In a clinical study of a consecutive group of 110 men with complaints of lifelong $\mathrm{PE}$, the duration of the IELT was measured by stopwatch operated by the woman partner [65]. Subjects were recruited by an advertisement offering treatment for $\mathrm{PE}$ and were not reimbursed for their participation. Men with ED, a history of alcohol abuse, and/or the current use of medication with sexual side effects were excluded. The diagnosis of lifelong $\mathrm{PE}$ was based on the self-reported occurrence of lifelong complaints of early ejaculation, and the patient expressed desire to delay ejaculation. The diagnosis was not based on application of the DSM-IV-TR or ICD-10 definitions of PE. The study showed that $40 \%$ of men ejaculated within 15 seconds, $70 \%$ within 30 seconds, and 90\% within 1 minute after penetration. Only 10\% ejaculated between 1 and 2 minutes. Participating couples reported that the use of a stopwatch did not significantly interfere with either sexual intercourse or the ejaculation time. Similar results were reported by McMahon in a retrospective case series of 1,346 consecutive men with $\mathrm{PE}$ and a mean IELT of 43.4 seconds [66]. These findings were confirmed in a third clinical study of 88 men with self-reported lifelong PE who actively sought treatment at a Sexual Disorder Outpatient Clinic. The diagnosis of PE was not based on application of the DSM-IV-TR or ICD-10 definition of PE [67]. In this study, IELT was self-estimated and a stopwatch was not used. This study showed that
$30 \%$ of men ejaculated within 15 seconds, $67 \%$ within 30 seconds, $92 \%$ within 1 minute, and $8 \%$ between 1 and 2 minutes after penetration.

These studies suggest that the majority of men who actively seek treatment for lifelong PE $(\sim 90 \%)$ ejaculate within 1 minute of penetration. In men who ejaculate between 1 and 2 minutes after penetration, only $10 \%$ actively seek treatment for lifelong PE. On the basis of this evidence, the committee determined that 1 minute was an appropriate IELT cutoff point. An IELT cutoff of 1 minute captures $90 \%$ of men with $\mathrm{PE}$ who actively seek treatment and parallels the (very) short ejaculation time criteria of the DSM-IV-TR and ICD-10 definitions of PE. Further qualification of this cutoff to "about 1 minute" affords the clinician sufficient flexibility to also diagnose $\mathrm{PE}$ in the $10 \%$ of $\mathrm{PE}$ treatment-seeking men who ejaculate within 1-2 minutes of penetration without unnecessarily stigmatizing the remaining $90 \%$ of men who ejaculate within 1-2 minutes of penetration but have no complaints of PE.

\section{The IELT in a Random Sample of Men in the General Male Population}

Most community-based epidemiological studies are limited by their reliance on either patient selfreport of PE or inconsistent and poorly validated definitions of PE. A recent industry-funded community-based age-ranging study of an unselected "normal" population of 500 heterosexual couples from five countries (the Netherlands, United Kingdom, Turkey, and Spain) involving stopwatch timing of the IELT during sexual intercourse has provided previously lacking normative IELT data [17]. This study demonstrated that the distribution of the IELT was positively skewed, with a median IELT of 5.4 minutes (range, 0.55 44.1 minutes). The median IELT decreased with age and varied between countries.

An epidemiological approach to assess disease risk and diagnostic criteria cutoff levels has been described for several diseases including osteoporosis, diabetes, and cardiovascular disease [68-72]. The prevalence of disease is by definition statistically limited to those members of the population within the 0.5 or the 2.5 percentile. In this study the authors regarded the 0.5 and 2.5 percentiles as acceptable standards of disease definition and reported that the 0.5 percentile equated to an IELT of 0.9 minute and the 2.5 percentile to an IELT of 1.3 minutes [17]. These normative data support the notion that IELTs of less than 1 
minute are statistically abnormal compared to men in the general Western population. Using the underlying principles of disease risk assessment and the results of analysis of this normative data, Waldinger et al. have proposed that lifelong PE is a neurobiological dysfunction with a high lifetime risk of developing sexual and psychological problems [33].

Based upon collective data that reports that $90 \%$ of men complaining of lifelong PE ejaculate within 1 minute and only $10 \%$ ejaculate within 1-2 minutes, Waldinger et al. proposed that men with an IELT of less than 1 minute (belonging to the 0.5 percentile) are definitely at risk of lifelong $\mathrm{PE}$ (definite PE). In addition, the authors proposed that men with IELTs between 1 and 1.5 minutes (between 0.5 and 2.5 percentile) have a significant but less risk of lifelong PE (probable PE), and are probably at risk of lifelong $\mathrm{PE}$ (probable $\mathrm{PE}$ ). The authors proposed that the severity of $\mathrm{PE}$ (non-symptomatic, mild, moderate, severe) is best defined by the presence and extent of associated psychological and sexual problems [33].

It should be noted that the use of the IELT as measure of ejaculatory performance has some limitations. The IELT can be confounded by several variables including the duration and content of foreplay, the sexual position, the depth, force, and frequency of penile thrusting, the period of time elapsed since the previous ejaculation, partner pelvic floor muscle tone, and the extent of partner vaginal lubrication. However, many of these confounders and the limitations they impose are only relevant in men with IELT values of more than 1 minute, where there is sufficient intercourse time for their impact to occur.

\section{Estimated IELT vs. Stopwatch IELT}

Several authors report that estimated and stopwatch IELT correlate reasonably well or are interchangeable in assigning PE status when estimated IELT is combined with PROs [73-75]. In an industry-funded study, Pryor et al. reported that non-PE men overestimate their IELT to a larger extent than men with PE and IELT estimations for PE men correlate reasonably well with stopwatch-recorded IELT [74]. In another industry-funded study, Rosen et al. described the reliability of combining patient-estimated IELT and PROs of ejaculatory control, sexual satisfaction, and personal distress in predicting PE [75]. With PRO response scores of either "good" or "a little bit," consistent with a DSM-IV-TR classification as non-PE or "poor" or "quite a bit," consistent with a DSM-IV-TR diagnosis of $\mathrm{PE}$, there was little variation in the probability of a $\mathrm{PE}$ diagnosis across a wide range of estimated IELT values (decreasing from $\sim 98 \%$ to $\sim 85 \%$ with increase in estimated IELT from 0 to 10 minutes). However, with mid-range PRO response scores of "fair" or "moderate," the probability of a PE diagnosis decreased from $\sim 65 \%$ to $18 \%$ with an increase in IELT from 0 to 10 minutes [74]. These findings do provide support for the use of self-estimation of IELT for the diagnosis of $\mathrm{PE}$ in clinical practice and as a measure of latency in a definition of PE.

This evidence (Table 1) strongly reinforces the value of including the construct of time-toejaculation in the ISSM definition of PE with the wording “....Ejaculation which always or nearly always occurs prior to or within about one minute of

Table 1 Findings of key publications regarding the time-to-ejaculate in PE

\begin{tabular}{|c|c|}
\hline Author/s & Summary of primary findings \\
\hline Waldinger et al. 1998 [65] & $\begin{array}{l}\text { - } 110 \text { men with lifelong PE whose IELT was measured by the use of a stopwatch } \\
\text { - } 40 \% \text { of men ejaculated within } 15 \text { seconds, } 70 \% \text { within } 30 \text { seconds, and } 90 \% \text { within } 1 \text { minute }\end{array}$ \\
\hline Waldinger et al. 2007 [67] & $\begin{array}{l}\text { - } 88 \text { men with lifelong PE who self-estimated IELT } \\
\text { - } 30 \% \text { of men ejaculated within } 15 \text { seconds, } 67 \% \text { within } 30 \text { seconds, and } 92 \% \text { within } 1 \text { minute } \\
\text { after penetration } \\
\text { - Only } 5 \% \text { ejaculated between } 1 \text { and } 2 \text { minutes }\end{array}$ \\
\hline Waldinger et al. 2005 [17] & $\begin{array}{l}\text { - Stopwatch IELT study in a random unselected group of } 491 \text { men in } 5 \text { countries } \\
\text { - IELT had a positive skewed distribution } \\
\text { - Application of } 0.5 \text { and } 2.5 \text { percentiles as disease standards } \\
\text { - } 0.5 \text { percentile equated to an IELT of } 0.9 \text { minute and } 2.5 \text { percentile to an IELT of } 1.3 \text { minutes }\end{array}$ \\
\hline Althof 1995 [73] & • IELT estimations for PE men correlate reasonably well with stopwatch-recorded IELT \\
\hline Pryor et al. 2005 [74] & - IELT estimations for PE men correlate reasonably well with stopwatch-recorded IELT \\
\hline Rosen et al. 2007 [75] & $\begin{array}{l}\text { - Self-estimated and stopwatch IELT as interchangeable } \\
\text { - Combining self-estimated IELT and PROs reliably predicts PE }\end{array}$ \\
\hline
\end{tabular}

$\mathrm{PE}=$ premature ejaculation; IELT = Intravaginal Ejaculation Latency Time; PRO = Patient Reported Outcome. 
vaginal penetration." Time-to-ejaculation can be either self-estimated by the patient or measured with a stopwatch.

\section{Inability to Delay Ejaculation (Ejaculatory Control)}

The ability to prolong sexual intercourse by delaying ejaculation and the subjective feelings of ejaculatory control comprise the complex construct of ejaculatory control. The ability to delay ejaculation may be either innate or learned by modulating sexual excitement. Although there has been some limited success in conditioning other autonomic reflexes, it has yet to be empirically demonstrated that the ejaculatory reflex can be brought under voluntary control. Nor has it been demonstrated that men who have voluntary control are controlling their ejaculatory reflex. Voluntary delay of ejaculation is most likely exerted either prior to or in the early stages of the emission phase of the reflex but progressively decreases until the point of ejaculatory inevitability [76,77]. Virtually all men report using at least one cognitive or behavioral technique to prolong intercourse and delay ejaculation, with varying degrees of success, and many young men reported using multiple different techniques [78].

Self-taught cognitive techniques invariably involve distracting thoughts, most commonly sexneutral cognitions such as thinking about sports, studies, or work, although a substantial proportion of men report using sex-negative cognitions that are specifically adverse to sexual arousal or focus upon negative consequences of sexual activity. The use of distracting thoughts is limited by the possible resultant decrease in the ability of men to attend to their partner's level of arousal and may interfere with overall sexual functioning by decreasing their sexual satisfaction, creation of a negative association with sexual intercourse or the development of ED, especially in older men [79]. Other behavioral techniques employed by men include preemptive ejaculation prior to intercourse, condom use, pre-coital consumption of alcohol, pelvic floor muscle contraction and relaxation, breathing techniques and/or rate-limiting techniques such as temporary withdrawal, slowing down thrusting, thrusting in a circular motion or different or alternating intercourse positions.

In general, the greater the number of techniques employed, the greater men's perceived ejaculatory control and IELT. Furthermore, there are no specific techniques that work for all men and the effectiveness of any specific technique at delaying ejaculation may be idiosyncratic to the man or to the particular situation.

\section{Rationale for the Inclusion of Inability to Delay Ejaculation in the ISSM Definition of PE}

Several authors have suggested that the inability to control or voluntarily delay ejaculation defines $\mathrm{PE}$ [80-84]. In an industry-funded internet survey of 1,158 research panel subjects, Rowland and coworkers classified 189 (16.3\%) as having probable PE based upon DSM-IV-TR criteria and reported that $49.7 \%$ of $\mathrm{PE}$ subjects rated their control over ejaculation as "poor" or "very poor" compared to $1.4 \%$ of non-PE subjects [85]. However, diminished feelings of ejaculatory control, the subjective aspect of ejaculatory control, is difficult to translate into quantifiable terms and is not exclusive to men suffering from $\mathrm{PE}$ [78]. Consistent with this, attempts to both operationalize control and characterize the relationship between control and latency have reported conflicting results, making comparison across subjects or across studies problematic $[18,65,78,86,87]$.

Grenier and Byers demonstrated a relatively weak correlation between ejaculatory latency and ejaculatory control $(\mathrm{R}=0.31)$, sharing less than $10 \%$ of their variance [78]. They reported that some men with a brief ejaculatory latency time reported adequate ejaculatory control and vice versa, and concluded that the dimensions of ejaculatory control and latency are distinct concepts. In a subsequent study, Grenier and Byers reported similar results, with latency and control sharing only $12 \%$ of their variance, suggesting that these PROs are relatively independent [86]. In an industry-funded study, McMahon et al. reported that sildenafil treatment of subjects with lifelong $\mathrm{PE}$ significantly improved the score in the control domain of the Index of Premature Ejaculation. However, sildenafil treatment failed to significantly increase IELT. This discrepancy between control domain scores and IELT is testament to a "disconnect" between ejaculatory latency and ejaculatory control [88].

Waldinger et al. also reported a relatively weak correlation between ejaculatory control and stopwatch IELT $(P=0.06)$ in a group of 110 men with lifelong PE and a mean stopwatch IELT of $28 \pm 29$ seconds [65]. Little or no control over ejaculation was reported by $41 \%$ of subjects during foreplay and by $98 \%$ of subjects during intercourse. Although $26 \%$ of subjects reported full 
control during foreplay, $95 \%$ of this group reported having little or no control during subsequent intercourse [65].

Contrary to this, several authors have reported a moderate correlation between the IELT and the feeling of ejaculatory control $[18,75,87,89]$. Rowland et al. compared multiple indices of erectile and ejaculatory response during coital and masturbatory activities in 26 men with $\mathrm{PE}$ and age-matched group of 13 sexually functional men [89]. The correlation between measures of ejaculatory latency and control was positive and high for intercourse ( $\mathrm{R}=0.81, P<0.001)$, but low or even negative for masturbation $(\mathrm{R}=-0.27, P=0.27)$. Whereas functional men showed consistency in ejaculatory latency over coital and masturbatory activities, PE men exhibited much shorter latencies during coitus than during masturbation.

The relationship between ejaculatory control, IELT, and a diagnosis of PE was explored in two large multicenter, industry-funded observational studies with similar methodologies of subjects recruited from advertisements seeking men with and without PE $[18,87]$. The diagnosis of PE was based purely on the application of the DSM-IV-TR definition of PE by clinicians: IELT was not a criterion to establish the diagnosis of PE. Both studies reported that men diagnosed with PE had significantly lower mean ratings of control over ejaculation $(P<0.0001) \quad[18,87]$. Patrick et al. observed that $72 \%$ of men with $P E$ reported ratings of "very poor" or "poor" for control over ejaculation compared to $5 \%$ in a group of normal controls [18]. Furthermore, more partners of PE subjects vs. partners of non-PE subjects gave ratings of "poor" or "very poor" for measures of control over ejaculation (53\% vs. $3 \%$, respectively). The strongest correlation between subject and partner measures was observed between the measure of control over ejaculation $(R=0.57)$. IELT was strongly positively correlated with control over ejaculation for subjects $(\mathrm{R}=0.51)$ and partners $(\mathrm{R}=0.46)$. Lower ratings for control over ejaculation were associated with shorter IELT, with "poor" or "very poor" control reported by $67.7 \%, 10.2 \%$, and $6.7 \%$ of subjects with IELT $<1$ minute, $>1$ minute, and $>2$ minutes, respectively. Giuliano et al. reported "good" or "very good" control over ejaculation in only $13.2 \%$ of PE subjects compared to $78.4 \%$ of non-PE subjects [87]. However, the DSM-IV-TR definition of PE is authority based and not evidence based, has no support from controlled clinical and/or epidemiological studies, and is multi-interpretable $[27,53]$. Its use limits the application of the study conclusions regarding the relationship between PROs and IELT to the general population of PE men [90].

Several authors have reported post-hoc analyses of U.S. observational data using path analysis, a form of regression analysis, to assess the relationships between the Pros and IELT in men diagnosed with PE [75,87,91].

Patrick et al. reported that IELT showed a significant direct effect on control over ejaculation but did not show a significant direct effect on ejaculation-related personal distress or satisfaction with sexual intercourse [91]. However, control over ejaculation did show a significant direct effect on both ejaculation-related personal distress and satisfaction with sexual intercourse, with each showing direct effects on interpersonal difficulty related to ejaculation. In this study, the effect of IELT upon satisfaction and distress appears to be mediated via its direct effect upon control. In this study population, the subject's perception of control over ejaculation is central to understanding how PE is associated with satisfaction with sexual intercourse and ejaculation-related distress. However, this study population had a mixed PE status and the relationship between control and IELT may differ in a more homogenous study group.

Rosen et al. used stepwise logistic regression analyses of several different linear models to assess the relationship between IELT and PROs and demonstrated that control over ejaculation and subject-assessed level of personal distress are more influential in determining PE status than IELT [75]. A subject reporting "very good" or "good" control over ejaculation is $90.6 \%$ less likely to have $\mathrm{PE}$ than a subject reporting "poor" or "very poor" control over ejaculation.

Giuliano et al. showed similar results in a path analysis of results obtained in the European observational study [87]. Correlation coefficients indicated that perceived control over ejaculation had a significant effect on satisfaction with sexual intercourse and personal distress related to ejaculation, whereas IELT did not have a direct effect on satisfaction with sexual intercourse and had only a small direct effect on ejaculation-related personal distress. These results support the notion that PE comprises a constellation of symptoms and is best diagnosed through a combination of IELT and validated, patient-reported set of PROs [92].

However, despite conflicting data on the relationship between control and latency, the balance of evidence supports the notion that the inability 
Table 2 Findings of key publications regarding ejaculatory control in PE

\begin{tabular}{|c|c|}
\hline Author/s & Summary of primary findings \\
\hline Grenier and Byers [78] & $\begin{array}{l}\text { - Relatively weak correlation between ejaculatory latency and ejaculatory control }(R=0.31) \\
\text { - Ejaculatory control and latency are distinct concepts }\end{array}$ \\
\hline Grenier and Byers [86] & $\begin{array}{l}\text { - Relatively poor correlation between ejaculatory latency and ejaculatory control, sharing only } 12 \% \text { of } \\
\text { their variance, suggesting that these PROs are relatively independent }\end{array}$ \\
\hline Waldinger et al. [65] & $\begin{array}{l}\text { - Little or no control over ejaculation was reported by } 98 \% \text { of subjects during intercourse } \\
\text { - Weak correlation between ejaculatory control and stopwatch IELT }(P=0.06)\end{array}$ \\
\hline Rowland et al. [89] & - High correlation between measures of ejaculatory latency and control $(R=0.81, P<0.001)$ \\
\hline Patrick et al. [18] & $\begin{array}{l}\text { - Men diagnosed with PE had significantly lower mean ratings of control over ejaculation }(P<0.0001) \\
\text { - } 72 \% \text { of men with PE reporting ratings of "very poor" or "poor" for control over ejaculation compared to } \\
5 \% \text { in a group of normal controls } \\
\text { - LELT was strongly positively correlated with control over ejaculation for subjects }(R=0.51)\end{array}$ \\
\hline Giuliano et al. [87] & $\begin{array}{l}\text { - Men diagnosed with PE had significantly lower mean ratings of control over ejaculation }(P<0.0001) \\
\text { - "Good" or "very good" control over ejaculation in only } 13.2 \% \text { of PE subjects compared to } 78.4 \% \text { of } \\
\text { - Perceived control over ejaculation had a significant effect on intercourse satisfaction and personal distress } \\
\text { - IELT did not have a direct effect on intercourse satisfaction and had only a small direct effect on personal } \\
\text { distress }\end{array}$ \\
\hline Patrick et al. [91] & - Effect of IELT upon satisfaction and distress appears to be mediated via its direct effect upon control \\
\hline Rosen et al. [75] & $\begin{array}{l}\text { - Control over ejaculation and subject-assessed level of personal distress are more influential in determining } \\
\text { - PE status than IELT } \\
\text { - Subject reporting "very good" or "good" control over ejaculation is } 90.6 \% \text { less likely to have PE than a } \\
\text { subject reporting "poor" or "very poor" control over ejaculation }\end{array}$ \\
\hline
\end{tabular}

PRO = Patient Reported Outcome; IELT = Intravaginal Ejaculation Latency Time; PE = premature ejaculation.

to delay ejaculation appears to differentiate men with PE from men without PE $[18,85,87]$. This evidence (Table 2) provides sufficient empirical support for the inclusion of the construct of inability to delay ejaculation in the ISSM definition of PE with the wording "... is characterized by ... the inability to delay ejaculation on all or nearly all vaginal penetrations."

\section{Negative Personal Consequences of PE}

$\mathrm{PE}$ has been associated with negative psychological outcomes in men and their women partners $[16,18,19,25,85,87,93-101]$. The personal and/or interpersonal distress that results from $\mathrm{PE}$ may affect men's quality of life and partner relationships and their self-esteem and self-confidence, and can act as an obstacle to single men forming new partner relationships [16,18,19,25,85,87,93101].

Personal and interpersonal distress first appeared in the definition of $\mathrm{PE}$ in the 1994 publication of the DSM-IV [27]. Speculation as to why distress was included focuses on the concern that individuals who have impairments of sexual function but were satisfied with their sexual life would be unduly stigmatized and/or coerced to accept unwanted treatment. Subsequent definitions of sexual dysfunctions and $\mathrm{PE}$, in particular, have maintained personal and/or interpersonal distress as a necessary criterion for diagnosis $[30,43,102]$.
Distress, however, may not be the most appropriate term to capture the negative psychosocial consequences associated with PE. Qualitative research conducted as part of the development of new PE PROs informs us that words such as bother, frustration, and annoyance more accurately reflect patients' and partners' subjective negative experiences [103]. This notion is reinforced by research in other disease entities such as benign prostatic hyperplasia, where bother has been accepted as the preferred term to capture the negative experiences associated with the disease [104].

Three forms of distress appear in the definitions of PE. They are personal distress for the man, personal distress for the partner, and interpersonal distress. The DSM-IV-TR includes all three forms of distress; the AUA and the ICSD-2 definitions include only personal and partner distress $[30,43,102]$. Partner and/or interpersonal distress, while important as negative psychosocial outcomes, would not be germane to the diagnosis of men with $\mathrm{PE}$ as not all men have partners.

\section{Rationale for the Inclusion of Negative Personal Consequences in the ISSM Definition of PE}

In the last decade several articles have appeared providing limited but sufficient evidence for the inclusion of personal distress in the definition of PE $[16,18,19,85,87,93-96,98,100,101]$. However, 
Table 3 Findings of key publications regarding the negative personal consequences of PE

\begin{tabular}{|c|c|}
\hline Author/s & Summary of primary findings \\
\hline Patrick et al. [18] & $\begin{array}{l}\text { Using the validated Premature Ejaculation Profile (PEP), } 64 \% \text { of men in the PE group vs. } 4 \% \text { in the non-PE } \\
\text { group reported personal distress }\end{array}$ \\
\hline Giuliano et al. [87] & On the PEP, $44 \%$ of men in the PE group vs. $1 \%$ of men in the non-PE group reported personal distress \\
\hline \multirow[t]{2}{*}{ Rowland et al. [95] } & Men in highly probable PE group reported greater distress vs. men in non-PE group on the PEP scale \\
\hline & $\begin{array}{l}\text { On the Self-Esteem and Relationship Questionnaire, men with highly probable PE had lower mean scores } \\
\text { overall, for confidence and self-esteem vs. non-PE men }\end{array}$ \\
\hline Rowland et al. [85] & $\begin{array}{l}30.7 \% \text { of probable PE group, } 16.4 \% \text { of possible PE group vs. } 7.7 \% \text { of non-PE group found it difficult to relax } \\
\text { and not be anxious about intercourse }\end{array}$ \\
\hline \multirow[t]{3}{*}{ Porst et al. [93] } & Depression reported by $20.4 \%$ of PE group vs. $12.4 \%$ of non-PE group \\
\hline & Excessive stress in $28 \%$ of PE group vs. $19 \%$ of non-PE group \\
\hline & Anxiety in $24 \%$ of PE group vs. $13 \%$ on non-PE group \\
\hline McCabe [96] & $\begin{array}{l}\text { Sexually dysfunction men, including those with PE, scored lower than sexually functional men on all } \\
\text { measures of intimacy on the Psychological and Interpersonal Relationship Scale }\end{array}$ \\
\hline \multirow[t]{2}{*}{ Symonds et al. [16] } & $\begin{array}{l}68 \% \text { reported self-esteem affected by PE. Decreased confidence in sexual encounter. } \\
\text { Anxiety reported by } 36 \% \text { (causing PE or because of it) }\end{array}$ \\
\hline & Embarrassment and depression also cited because of $\mathrm{PE}$ \\
\hline Dunn et al. [94] & Strong association of PE with anxiety and depression on the Hospital and Anxiety Scale \\
\hline Hartmann et al. [25] & $\begin{array}{l}58 \% \text { of } \mathrm{PE} \text { group reported partner's behavior and reaction to PE was positive and } 23 \% \text { reported it was } \\
\text { negative }\end{array}$ \\
\hline Byers et al. [97] & $\begin{array}{l}\text { Men with PE and their partners reported slightly negative impact of PE on personal functioning and sexual } \\
\text { relationship but no negative impact on overall relationship }\end{array}$ \\
\hline
\end{tabular}

$\mathrm{PE}=$ premature ejaculation.

the data are not as strong for the inclusion of interpersonal distress $[25,97]$. These reports employed different methods to assess distress in men with PE, their partners, and the relationship. They include quantitative validated questionnaires, non-validated measures, Internet surveys, postal surveys, and thematic assessment of qualitative reviews.

Ten studies examined the psychosocial and quality-of-life consequences associated with $\mathrm{PE}$ men and their partners (Table 3) $[16,18,25,85$, 87,93-98]. Despite the use of different methodologies and outcome measures, all these studies suggest that $\mathrm{PE}$ is associated with negative consequences for the man, his partner, and their relationship.

For example, Patrick et al. conducted a 4-week industry-funded observational study of 1,587 men, with 207 diagnosed with PE by clinicians employing DSM-IV-TR criterion and with 1,380 judged by clinicians not to have PE [18]. Partner-held stopwatch IELTs were recorded for each intercourse event, and men and their partners independently completed four PROs assessing control over ejaculation, satisfaction with sexual intercourse, personal distress, and interpersonal difficulty.

There were significant differences in the responses of men with and without PE in responding to the PRO questions measuring personal distress, interpersonal difficulty, and satisfaction. Contrasting men with and without PE, 64\% vs. $4 \%$ of men reported being "quite a bit" or "extremely" personally distressed, while $31 \%$ vs. $1 \%$ indicated "quite a bit" or "extremely" distressed for interpersonal difficulty and $31 \%$ vs. $1 \%$ reported rated "very poor" or "poor" for satisfaction with sexual intercourse. The divergent pattern observed for personal distress suggests that this construct has discriminative validity in diagnosing men with and without PE. The data for satisfaction and interpersonal distress, while statistically significant, were not as strong.

Similarly, in a recent, large European industryfunded observational study using the same four questions (the Premature Ejaculation Profile), Giuliano et al. demonstrated that substantially more men with PE and their partners were "extremely" or "quite a bit" distressed compared to the non-PE groups (43.9\% vs. $1.4 \%$ for men; $30.2 \%$ vs. $1.0 \%$ for partners) [87]. Finally, in both Patrick et al.'s and Giuliano et al.'s studies a moderate correlation between the couples' ratings for personal distress $(r=0.53, r=0.49$, respectively) was observed, adding to the convincing body of evidence regarding the negative psychosocial outcome for this dysfunction [18,87].

Additionally, 4 of 11 studies showed that PE has a marked effect on the quality of life of men (Table 1) [16,19,94,95]. McCabe reported that sexually dysfunctional men, including men with $\mathrm{PE}$, scored lower on all aspects of intimacy (emotional, social, sexual, recreational, and intellectual) and had lower levels of satisfaction compared to sexually functional men $(P<0.001$ or $P<0.01)$ 
[96]. In an industry-funded study, Rowland et al. showed that men with PE had significantly lower total Self-Esteem And Relationship Questionnaire scores and lower confidence and self-esteem compared to non-PE groups (all $P \leq 0.001$ ) [95]. PE men rated their overall health-related quality of life lower than men without PE $(P \leq 0.001$ or $P \leq 0.006)$. Symonds et al. and Dunn et al. independently demonstrated a strong association between sexual confidence, anxiety, and in some cases depression with PE $[16,94]$.

This evidence (Table 3) reinforces the value of including personal distress in the ISSM definition of $\mathrm{PE}$ with the wording "is characterized by ... negative personal consequences, such as distress, bother, frustration and/or the avoidance of sexual intimacy." Distress, frustration, and/or bother capture the negative psychological consequences of $\mathrm{PE}$ and are important constructs that discriminate between men with $\mathrm{PE}$ and those without PE. As some men do not have partners and as partner distress and interpersonal distress are not universally applicable to all men, partner distress and interpersonal distress should not be included in the definition of PE $[25,97]$.

\section{Sexual Satisfaction}

Men with PE report lower levels of sexual satisfaction compared to men with normal ejaculatory latency $[18,87]$.

\section{Rationale for the Exclusion of Satisfaction in the ISSM definition of PE}

Patrick et al. reported ratings of "very poor" or "poor" for sexual satisfaction in $31 \%$ of subjects with $\mathrm{PE}$ compared to $1 \%$ in a group of normal controls [18]. Furthermore, more partners of PE subjects vs. partners of non-PE subjects gave ratings of "poor" or "very poor" for measures of sexual satisfaction with sexual intercourse $(28 \%$ vs. $2 \%$, respectively). However, caution should be exercised in assigning lower levels of sexual satisfaction solely to the effect of $\mathrm{PE}$, and contributions from other issues that are difficult to quantify such as reduced intimacy, dysfunctional relationships, poor sexual attraction, and poor communication should not be ignored. This is supported by the report of Patrick et al. that despite reduced ratings for satisfaction with shorter IELTs with "poor" or "very poor" intercourse satisfaction reported by $25.4 \%, 3.6 \%$, and $2.0 \%$ of subjects with an IELT $<1$ minute, $>1$ minute, and $>2$ minutes, respec- tively, a substantial proportion of men with an IELT < 1 minute report "good" or "very good" satisfaction ratings $(43.7 \%)$. The current data are limited but suggest that sexual satisfaction is of limited use in differentiating PE subjects from non-PE subjects and has not been included in the ISSM definition of PE [18]. Clearly, additional research is required to improve our understanding of the relationship between sexual satisfaction and ejaculatory performance.

\section{Conclusion}

In the last decade, substantial progress has been made in the development of the evidence-based methodology of PE epidemiological and drug treatment research using the objective IELT and subjective validated PROs. However, this research has been restricted by the lack of an evidencedbased definition of PE. Existing definitions of PE are vague, multi-interpretable, primarily conceptual in nature, lack specific operational criteria, and rely to a large extent on expert opinion without explicit critical appraisal rather than on the findings of evidence-based clinical research.

Evidence-based definitions seek to limit errors of classification and thereby increase the likelihood that existing and newly developed therapeutic strategies are truly effective in carefully selected dysfunctional populations [39]. One method of decreasing diagnostic errors is to employ a multivariate definition with several diagnostic criteria rather than a single, specified IELT cutoff point. Such a definition serves to broaden the focus of clinicians and investigators from the IELT alone by inclusion of important subjective variables such as perceived control and distress/bother regarding ejaculatory latency. A multivariate definition of $\mathrm{PE}$ provides the clinician a more discriminating diagnostic tool. If a multivariate definition is used, men who ejaculate in less than 1 minute but report adequate control and no personal negative consequences related to their rapid ejaculation do not merit the diagnosis of PE. Similarly, men who have IELTs of 10 minutes but report poor control, dissatisfaction, and personal negative consequences also fail to meet the criteria for PE.

Although there have been several recent large evidence-based observational studies, many are methodologically flawed and there is an urgent need for standardization of PE observational, intervention, and intervention preference trial methodology. The methodology of many of these studies is polarized, either focusing on IELT alone 
with scant attention to PROs or concentrating upon the PROs of control, satisfaction, and distress in men diagnosed as having PE by application of the DSM-IV-TR with IELTs as high as 20 minutes. Conclusions regarding the relationship between PROs and IELT based on data from studies with inadequately selected trial groups must be regarded with some caution and cannot be reliably generalized to subjects with this condition.

After critical evaluation of the published data, the committee unanimously agreed that the constructs that are necessary to define $\mathrm{PE}$ are time from penetration to ejaculation, inability to delay ejaculation, and negative personal consequences from $\mathrm{PE}$ and recommended the following definition of lifelong PE.

Lifelong PE is a male sexual dysfunction characterized by

- ejaculation that always or nearly always occurs prior to or within about 1 minute of vaginal penetration;

- the inability to delay ejaculation on all or nearly all vaginal penetrations; and

- negative personal consequences such as distress, bother, frustration, and/or the avoidance of sexual intimacy.

The committee also agreed that the 1-minute IELT cutoff point should not be applied in the most absolute sense, as about $10 \%$ of men seeking treatment for lifelong PE have IELTs of 1-2 minutes. The phrase "within about 1 minute" must be interpreted as giving the clinician sufficient flexibility to diagnose $\mathrm{PE}$ also in men who report an IELT as long as 90 seconds. A diminished ability to delay ejaculation is only valid as a criterion of lifelong PE if the same individual always or nearly always ejaculates within about 1 minute. The ISSM definition of lifelong PE is intended to serve as an international standard for defining this common sexual dysfunction. It is not intended to be a means of measuring the effect of the pharmacologic treatment of $\mathrm{PE}$ or to erroneously suggest that improving control and reducing distress without improving the IELT indicates drug efficacy.

This definition intentionally embodies a degree of diagnostic conservatism and flexibility for several reasons. First, a conservative and flexible definition provides a more realistic prevalence of the dysfunction. Second, it would help to establish $\mathrm{PE}$ as a bona fide sexual dysfunction rather than a lifestyle condition where men are simply seeking to enhance their sexual function. Third, it would help to ensure greater confidence in the efficacy of new and existing treatments and strengthen the likelihood that regulatory agencies might approve new efficacious and safe compounds for this dysfunction [39].

A limitation of the definition is its application to only heterosexual men engaging in vaginal intercourse. However, as there are few studies available on $\mathrm{PE}$ research in homosexual men, and as the major focus of the committee was to formulate a definition on evidence-based data, it has been decided to restrict the definition to heterosexual men engaging in vaginal intercourse.

After a critical evaluation of the published data, the committee was unable to identify sufficient published objective data to craft an evidencebased definition of acquired PE. It is hoped that future studies will generate data to formulate such a definition. The committee encourages further research into acquired $\mathrm{PE}, \mathrm{PE}$ in homosexual men, and $\mathrm{PE}$ during other forms of heterosexual sexual expression.

We are grateful to the ISSM for its leadership in assembling and encouraging the committee members in devising the evidence-based PE definition. We hope this definition will encourage and facilitate further research into the prevalence of both lifelong and acquired PE, the development of new tools and PROs for both the diagnosis and assessment of treatment outcomes, and the development of new pharmacologic and psychological treatment.

\section{Acknowledgments}

The ISSM Ad Hoc Committee for the Definition of Premature Ejaculation: G. Adaikan (Singapore), S. Althof (USA), E. Becher (Argentina), G. Broderick (USA), J. Buvat (France), K. Dabees (Egypt), J. Dean (facilitator; UK), A. Giraldi (Denmark), F. Giuliano (France), W. Hellstrom (USA), L. Incrocci (the Netherlands), E. Laan (the Netherlands), C.G. McMahon (Australia), E. Meuleman (the Netherlands), M. Perelman (USA), H. Porst (chairman; Germany), R. Rosen (USA), D. Rowland (USA), T. Segraves (USA), I. Sharlip (USA), M.D. Waldinger (the Netherlands).

The ISSM Ad Hoc Committee for the Definition of Premature Ejaculation was supported by unrestricted grants from Plethora Solutions and Johnson \& Johnson.

We finally wish to extend special thanks to Robert Kessler and David Casolod (ISSM Secretariat) and Astrid Brendt (AB Solutions) for providing administrative and logistic support.

We wish to thank the following external, independent reviewers for their advice: Pierre Assalian 
(Canada), Emmanuele Jannini (Italy), Michael Metz (USA), Donald Strassberg (USA), and Carmita Abdo (Brazil).

Corresponding Author: Chris G. McMahon, MD, University of Sydney, Australian Centre for Sexual Health, Suite 2-4, Berry Road Medical Centre, 1a Berry Road St. Leonards NSW Australia 2071. Tel: +61 2 94373906; Fax: +61 2 99065900; E-mail: cmcmahon@ acsh.com.au

Conflict of Interest: C.G. McMahon: Johnson \& Johnson-Consultant, Principal Investigator, Advisory Board, Speaker; Bayer Schering-Investigator, Advisory Board, Speaker; Pfizer-Advisory Board, Principal Investigator, Speaker; Plethora Solutions-Advisory Board, Speaker; Futura Medical-Advisory Board; Rexhana-Advisory Board. S. Althof: Bio-SantePrincipal Investigator; Boeringer Ingelheim-Sub Investigator; GSK-Advisory Board, Consultant; Johnson \& Johnson-Advisory Board, Speaker; Lilly-Advisory Board, Speaker; Palitan-Advisory Board, Speaker; Pfizer-Speaker; Plethora-Advisory Board, Principal Investigator; sanofi-aventisAdvisory Board. M.D. Waldinger: Pfizer-Principal Investigator; Plethora Solutions-Advisory Board, Speaker. H. Porst: Johnson \& Johnson-Consultant, Investigator, Speaker; Cilag-Janssen-Consultant, Investigator, Speaker; Bayer Schering-Consultant, Investigator, Speaker; Lilly-Consultant, Investigator, Speaker; Pfizer-Consultant, Investigator, Speaker. J. Dean: Bayer Schering-Consultant; PfizerConsultant; Lilly-Consultant; BoehringerIngelheim-Consultant; Pro-Strakan-Consultant; Plethora Solutions-Consultant; Johnson \& Johnson-Consultant. I. Sharlip: Johnson \& Johnson-Consultant, Speaker; Lilly-Consultant, Speaker; Pfizer-Consultant, Speaker; Plethora Solutions-Advisory Board.

\section{References}

1 Schapiro B. Premature ejaculation, a review of 1130 cases. J Urol 1943;50:374-9.

2 Semans JH. Premature ejaculation: A new approach. South Med J 1956;49:353-8.

3 Masters WH, Johnson VE. Human sexual inadequacy. Boston: Little Brown; 1970:92-115.

4 Eaton H. Clomipramine in the treatment of premature ejaculation. J Int Med Res 1973;1:432-4.

5 Assalian P. Clomipramine in the treatment of premature ejaculation. J Sex Res 1988;24:213-5.

6 Waldinger MD, Hengeveld M. Neuroseksuologie en seksuele psychofarmacologie. Tijdschr Psychiatr 2000;8:585-93.

7 Olivier B, van Oorschot R, Waldinger MD. Serotonin, serotonergic receptors, selective serotonin reuptake inhibitors and sexual behaviour. Int Clin Psychopharmacol 1998;13(6 suppl):S9-14.
8 Waldinger MD, Rietschel M, Nothen MM, Hengeveld MW, Olivier B. Familial occurrence of primary premature ejaculation. Psychiatr Genet 1998;8:37-40.

9 Waldinger M, Olivier B. Hersenonderzoek en farmacologie: serotonine, seks en agressie. In: Wolters-Schweitzer MHJ, Beuger CL, eds. Het Brein Belicht: Opstellen over Niet-Aangeboren Hersenletsel. Utrecht: Uitgeverij Lemma; 2001: 55-63.

10 Pattij T, Olivier B, Waldinger MD. Animal models of ejaculatory behavior. Curr Pharm Des 2005; 11:4069-77.

11 Olivier B, Chan JS, Pattij T, de Jong TR, Oosting RS, Veening JG, Waldinger MD. Psychopharmacology of male rat sexual behavior: Modeling human sexual dysfunctions? Int J Impot Res 2006;18(1 suppl):S14-23.

12 Giuliano F, Clement P. Serotonin and premature ejaculation: From physiology to patient management. Eur Urol 2006;50:454-66.

13 Waldinger MD, Zwinderman AH, Schweitzer DH, Olivier B. Relevance of methodological design for the interpretation of efficacy of drug treatment of premature ejaculation: A systematic review and meta-analysis. Int J Impot Res 2004; 16:369-81.

14 Metz ME, Pryor JL, Nesvacil LJ, Abuzzahab F Sr., Koznar J. Premature ejaculation: A psychophysiological review. J Sex Marital Ther 1997;23:323.

15 Metz ME, Pryor JL. Premature ejaculation: A psychophysiological approach for assessment and management. J Sex Marital Ther 2000;26:293320.

16 Symonds T, Roblin D, Hart K, Althof S. How does premature ejaculation impact a man's life? J Sex Marital Ther 2003;29:361-70.

17 Waldinger MD, Quinn P, Dilleen M, Mundayat R, Schweitzer DH, Boolell M. A multinational population survey of intravaginal ejaculation latency time. J Sex Med 2005;2:492-7.

18 Patrick DL, Althof SE, Pryor JL, Rosen R, Rowland DL, Ho KF, McNulty P, Rothman MJ, Jamieson C. Premature ejaculation: An observational study of men and their partners. J Sex Med 2005;2:58-367.

19 Rosen R, Althof S. Psychological consequences of $\mathrm{PE}$, quality of life and impact on sexual relationships. J Sex Med 2008 (in press).

20 Rowland D, Cooper S, Macias L. Pharmaceutical companies could serve their own interests by supporting research on the efficacy of psychotherapy on premature ejaculation. Int $\mathrm{J}$ Impot Res 2008;20:115-20.

21 Waldinger MD. Premature ejaculation: Definition and drug treatment. Drugs 2007;67:547-68.

22 Screponi E, Carosa E, Di Stasi SM, Pepe M, Carruba G, Jannini EA. Prevalence of chronic 
prostatitis in men with premature ejaculation. Urology 2001;58:198-202.

23 Carani C, Isidori AM, Granata A, Carosa E, Maggi M, Lenzi A, Jannini EA. Multicenter study on the prevalence of sexual symptoms in male hypo- and hyperthyroid patients. J Clin Endocrinol Metab 2005;90:6472-9.

24 Laumann EO, Nicolosi A, Glasser DB, Paik A, Gingell C, Moreira E, Wang T. Sexual problems among women and men aged 40-80 y: Prevalence and correlates identified in the Global Study of Sexual Attitudes and Behaviors. Int J Impot Res 2005;17:39-57.

25 Hartmann U, Schedlowski M, Kruger TH. Cognitive and partner-related factors in rapid ejaculation: Differences between dysfunctional and functional men. World J Urol 2005;10:10.

26 Waldinger MD, Schweitzer DH. Changing paradigms from a historical DSM-III and DSM-IV view toward an evidence-based definition of premature ejaculation. Part II-proposals for DSM-V and ICD-11. J Sex Med 2006;3:693-705.

27 American Psychiatric Association. Diagnostic and Statistical Manual of Mental Disorders, DSM-IV. 4th edition. Washington, DC: American Psychiatric Association; 1994:509-11.

28 World Health Organization. International Classification of Diseases and Related Health Problems. 10th edition. Geneva: World Health Organization; 1994.

29 Metz M, McCarthy B. Coping with premature ejaculation: How to overcome PE, please your partner and have great sex. Oakland, CA: New Harbinber Publications; 2003.

30 Montague DK, Jarow J, Broderick GA, Dmochowski RR, Heaton JP, Lue TF, Nehra A, Sharlip ID. AUA guideline on the pharmacologic management of premature ejaculation. J Urol 2004;172: 290-4.

31 Colpi G, Weidner W, Jungwirth A, Pomerol J, Papp G, Hargreave T, Dohle G. EAU guidelines on ejaculatory dysfunction. Eur Urol 2004;46: 555-8.

32 McMahon CG, Abdo C, Incrocci I, Perelman M, Rowland D, Stuckey B, Waldinger M, Xin ZC. Disorders of orgasm and ejaculation in men. In: Lue TF, Basson R, Rosen R et al., eds. Sexual medicine: Sexual dysfunctions in men and women (2nd International Consultation on Sexual Dysfunctions-Paris). Paris: Health Publications; 2004:409-68.

33 Waldinger MD, Zwinderman AH, Olivier B, Schweitzer DH. Proposal for a definition of lifelong premature ejaculation based on epidemiological stopwatch data. J Sex Med 2005;2:498507.

34 Jannini EA, Lombardo F, Lenzi A. Correlation between ejaculatory and erectile dysfunction. Int J Androl 2005;28(2 suppl):40-5.
35 Centre for Evidence-Based Medicine. Oxford Centre for Evidence-Based Medicine Levels of Evidence. 2001. Available at http://www.cebm.net/ index.aspx? o=1025 (accessed February 8, 2008).

36 Althof SE, Symonds T. Patient reported outcomes used in the assessment of premature ejaculation. Urol Clin North Am 2007;34:581-9.

37 Sackett DL, Rosenberg WM, Gray JA, Haynes RB, Richardson WS. Evidence based medicine: What it is and what it isn't. BMJ 1996;213:71-2.

38 Cronbach LJ, Meehl PE. Construct validity in psychological tests. Psychol Bull 1955;52:281-302.

39 Althof S, Rowland D. Identifying constructs and criteria for the diagnosis of premature ejaculation: Implication for making errors of classification. BJU Int 2008 (in press).

40 Waldinger MD. The need for a revival of psychoanalytic investigations into premature ejaculation. J Mens Health Gend 2006;3:390-6.

41 American Psychiatric Association. Diagnostic and Statistical Manual of Mental Disorders, DSM-IIII. 3rd edition. Washington, DC: American Psychiatric Association; 1980.

42 American Psychiatric Association. Diagnostic and Statistical Manual of Mental Disorders, DSMIIII-R. 3rd edition Revised. Washington, DC: American Psychiatric Association; 1987.

43 American Psychiatric Association. Diagnostic and Statistical Manual of Mental Disorders, DSMIV-TR. 4th edition Revised. Washington, DC: American Psychiatric Association; 2000.

44 Cooper AJ, Magnus RV. A clinical trial of the beta blocker propranolol in premature ejaculation. J Psychosom Res 1984;28:331-6.

45 Spiess WF, Geer JH, O’Donohue WT. Premature ejaculation: Investigation of factors in ejaculatory latency. J Abnorm Psychol 1984;93:242-5.

46 Strassberg DS, Mahoney JM, Schaugaard M, Hale VE. The role of anxiety in premature ejaculation: A psychophysiological model. Arch Sex Behav 1990;19:251-7.

47 Strassberg DS, Kelly MP, Carroll C, Kircher JC. The psychophysiological nature of premature ejaculation. Arch Sex Behav 1987;16:327-36.

48 LoPiccolo J. Direct treatment of sexual dysfunction in the couple. In: Money J, Mesaph H, eds. Handbook of sexologyed: Vol. 5. Selected syndromes and therapy. New York: Elsevier; 1978: 1227-44.

49 Kilmann PR, Auerbach R. Treatments of premature ejaculation and psychogenic impotence: A critical review of the literature. Arch Sex Behav 1979;8:81-100.

50 Trudel G, Proulx S. Treatment of premature ejaculation by bibliotherapy: An experimental study. Sex Marital Ther 1987;2:163-7.

51 Zeiss RA, Christensen A, Levine AG. Treatment for premature ejaculation through male-only groups. J Sex Marital Ther 1978;4:139-43. 
52 Schover L, Friedman J, Weiler S, Heiman J, LoPiccolo J. Multiaxial problem-oriented system for sexual dysfunctions. Arch Gen Psychiatry 1982; 39:614-9.

53 Waldinger MD, Schweitzer DH. Changing paradigms from a historical DSM-III and DSM-IV view toward an evidence-based definition of premature ejaculation. Part I-validity of DSM-IVTR. J Sex Med 2006;3:682-92.

54 O'Donohue W, Letourneau EJ, Geer JH. Premature ejaculation. In: O'Donohue $W$, ed. Handbook of sexual dysfunctions. New York: GJ Simon Schuster; 1993:303-33.

55 Waldinger MD. The neurobiological approach to premature ejaculation. J Urol 2002;168:2359-67.

56 Waldinger MD, Schweitzer DH. The use of old and recent DSM definitions of premature ejaculation in observational studies: A contribution to the present debate for a new classification of $\mathrm{PE}$ in the DSM-V. J Sex Med 2008;5:1079-87.

57 Waldinger MD, Schweitzer DH. The DSMIV-TR is an inadequate diagnostic tool for premature ejaculation. J Sex Med 2007;4:822-3.

58 Segraves R, Balon R, Clayton A. Proposal for changes in diagnostic criteria for sexual dysfunctions. J Sex Med 2007;4:567-80.

59 Segraves RT, Balon R. Toward an improved nosology of sexual dysfunctions in DSM-V. Psychiatric Times 2007;24:44-6.

60 Balon R, Segraves RT, Clayton A. Issues for DSM-V: Sexual dysfunction, disorder, or variation along normal distribution: Toward rethinking DSM criteria of sexual dysfunctions. Am J Psychiatry 2007;164:198-9.

61 Hellstrom WJ. The DSM-IV-TR is an appropriate diagnostic tool for premature ejaculation. J Sex Med 2007;4:252.

62 Shabsigh R, Rowland D. The diagnostic and statistical manual of mental disorders, fourth edition, text revision as an appropriate diagnostic for premature ejaculation. J Sex Med 2007;4:1468-78.

63 Waldinger MD, Hengeveld MW, Zwinderman AH. Paroxetine treatment of premature ejaculation: A double blind, randomized, placebo controlled study. Am J Psychiatry 1994;151:13779.

64 Waldinger MD. Four measures of investigating ejaculatory performance. J Sex Med 2007;4:520.

65 Waldinger $M$, Hengeveld $M$, Zwinderman A, Olivier B. An empirical operationalization of DSM-IV diagnostic criteria for premature ejaculation. Int J Psychiat Clin Pract 1998;2:287-93.

66 McMahon CG. Long term results of treatment of premature ejaculation with selective serotonin re-uptake inhibitors. Int J Impot Res 2002;14(3 suppl):S19.

67 Waldinger MD, Zwinderman AH, Olivier B, Schweitzer DH. The majority of men with lifelong premature ejaculation prefer daily drug treatment:
An observation study in a consecutive group of Dutch men. J Sex Med 2007;4:1028-37.

68 Kanis JA, Johnell O, Oden A, Johnsson B, de Laet C, Dawson A. Risk of hip fracture according to the World Health Organization criteria for osteopenia and osteoporosis. Bone Marrow Transplant 2000; 27:585-90.

69 World Health Organization. Assessment of fracture risk and its application to screening for postmenopausal osteoporosis. WHO Technical Report Series 843. Geneva: WHO; 1994.

70 World Health Organization. Guidelines for preclinical evaluation and clinical trials in osteoporosis. Geneva: WHO; 1998.

71 World Health Organization. Definition, diagnosis and classification of diabetes mellitus and its complications. Part 1: Diagnosis and classification of diabetes mellitus. Geneva: WHO; 1999.

72 Expert Panel on Detection Evaluation and Treatment of High Blood Cholesterol in Adults. Executive summary of the third report of the National Cholesterol Education Program (NCEP) Expert Panel on Detection, Evaluation, and Treatment of High Blood Cholesterol in Adults (Adult Treatment Panel III). JAMA 2001;285:2486-97.

73 Althof SE, Levine SB, Corty EW, Risen CB, Stern EB, Kurit DM. A double-blind crossover trial of clomipramine for rapid ejaculation in 15 couples. J Clin Psychiatry 1995;56:402-7.

74 Pryor JL, Broderick GA, Ho KF, Jamieson C, Gagnon D. Comparison of estimated versus measured Intravaginal Ejaculatory Latency Time (IELT) in men with and without Premature Ejaculation (PE). J Sex Med 2005;3:54.

75 Rosen RC, McMahon CG, Niederberger C, Broderick GA, Jamieson C, Gagnon DD. Correlates to the clinical diagnosis of premature ejaculation: Results from a large observational study of men and their partners. J Urol 2007;177:1059-64.

76 McMahon CG, Waldinger M, Rowland DL, Assalian P, Chan Kim Y, Bechara A, Riley A. Ejaculatory disorders. In: Porst H, Buvat J, eds. Standard practice in sexual medicine. Oxford: Blackwell Publishing; 2006:188-209.

77 Perelman MA. A new combination treatment for premature ejaculation: A sex therapist's perspective. J Sex Med 2006;3:1004-12.

78 Grenier G, Byers ES. The relationships among ejaculatory control, ejaculatory latency, and attempts to prolong heterosexual intercourse. Arch Sex Behav 1997;26:27-47.

79 Cranston-Cuebas MA, Barlow DH. Cognitive and affective contributions to sexual functioning. Ann Rev Sex Res 1990;1:119-61.

80 Kaplan HS, Kohl RN, Pomeroy WB, Offit AK, Hogan B. Group treatment of premature ejaculation. Arch Sex Behav 1974;3:443-52.

81 Zilbergeld B. Male sexuality. Toronto: Bantam; 1978. 
82 Perelman M. Treatment of premature ejaculation. In: Pervin L, ed. Principles and practices of sex therapy. New York: Guilford Press; 1980:199_ 233.

83 Vandereycken $W$. Towards a better delineation of ejaculatory disorders. Acta Psychiatr Belg 1986; 86:57-63.

84 McCarthy B. Cognitive-behavioural strategies and techniques in the treatment of early ejaculation. In: Leiblum SR, Rosen R, eds. Principles and practices of sex therapy: Update for the 1990's. New York: Guilford Press; 1988:141-67.

85 Rowland D, Perelman M, Althof S, Barada J, McCullough A, Bull S, Jamieson C, Ho KF. Selfreported premature ejaculation and aspects of sexual functioning and satisfaction. J Sex Med 2004;1:225-32.

86 Grenier G, Byers S. Operationalizing premature or rapid ejaculation. J Sex Res 2001;38:369-78.

87 Giuliano F, Patrick DL, Porst H, La Pera G, Kokoszka A, Merchant S, Rothman M, Gagnon DD, Polverejan E. Premature ejaculation. Results from a five-country European observational study. Eur Urol 2008;53:1048-57.

88 McMahon CG, Stuckey B, Andersen ML. Efficacy of viagra: Sildenafil citrate in men with premature ejaculation. J Sex Med 2005;2:368-75.

89 Rowland DL, Strassberg DS, de Gouveia Brazao CA, Slob AK. Ejaculatory latency and control in men with premature ejaculation: An analysis across sexual activities using multiple sources of information. J Psychosom Res 2000;48:69-77.

90 McMahon CG. The DSM-IV-TR definition of premature ejaculation and its impact upon the results of epidemiological studies. Eur Urol 2008;53:887-9.

91 Patrick DL, Rowland D, Rothman M. Interrelationships among measures of premature ejaculation: The central role of perceived control. J Sex Med 2007;4:780-8.

92 McMahon CG. Ejaculatory latency vs. patientreported outcomes (PROs) as study end points in premature ejaculation clinical trials. Eur Urol 2007;52:321-3.

93 Porst H, Montorsi F, Rosen RC, Gaynor L, Grupe $\mathrm{S}$, Alexander J. The Premature Ejaculation Prevalence and Attitudes (PEPA) survey: Prevalence, comorbidities, and professional help-seeking. Eur Urol 2007;51:816-23.

94 Dunn KM, Croft PR, Hackett GI. Association of sexual problems with social, psychological, and physical problems in men and women: A cross sectional population survey. J Epidemiol Community Health 1999;53:144-8.

95 Rowland DL, Patrick DL, Rothman M, Gagnon DD. The psychological burden of premature ejaculation. J Urol 2007;177:1065-70.

96 McCabe MP. Intimacy and quality of life among sexually dysfunctional men and women. J Sex Marital Ther 1997;23:276-90.

97 Byers ES, Grenier G. Premature or rapid ejaculation: Heterosexual couples' perceptions of men's ejaculatory behavior. Arch Sex Behav 2003;32:26170.

98 Riley A, Riley E. Premature ejaculation: Presentation and associations. An audit of patients attending a sexual problems clinic. Int J Clin Pract 2005;59:1482-7.

99 Brock GB, Gajewski J, Carrier S, Bernard F, Lee J, Pommerville PJ. The prevalence and impact of premature ejaculation in Canada. In Proceedings of Annual Meeting of the American Urological Association. May 19-24, 2007. Anaheim, CA.

100 Althof SE. Prevalence, characteristics and implications of premature ejaculation/rapid ejaculation. J Urol 2006;175:842-8.

101 Althof S. The psychology of premature ejaculation: Therapies and consequences. J Sex Med 2006;3(4 suppl):324-31.

102 McMahon C, Abdo C, Incrocci L, Perelman M, Rowland D, Waldinger M, Xin ZC. Disorders of orgasm and ejaculation in men. J Sex Med 2004; $1: 58-65$.

103 Althof S, Rosen R, Symonds T, Mundayat R, May $\mathrm{K}$, Abraham L. Development and validation of a new questionnaire to assess sexual satisfaction, control, and distress associated with premature ejaculation. J Sex Med 2006;3:465-75.

104 Barry MJ, Fowler FJ Jr., O’Leary, MP, Bruskewitz RC, Holtgrewe HL, Mebust WK, Cockett AT. The American Urological Association symptom index for benign prostatic hyperplasia. The Measurement Committee of the American Urological Association. J Urol 1992;148:1549-57. 